\title{
The influence of hydraulic conditions on coagulation process effectiveness
}

\author{
Aleksandra Sambor ${ }^{1, *}$, and Zbigniew Ferenc $^{1}$ \\ ${ }^{1}$ Wroclaw University of Science and Technology, Faculty of Environmental Engineering, Wybrzeze \\ Wyspianskiego 27, 50-370 Wroclaw, Poland
}

\begin{abstract}
This paper presents the impact that small changes in the hydraulic installation between the flocculation chamber and the sedimentation tanks have on coagulation process effectiveness. This study has shown significant improvements in the parameters of the treated water. The research was conducted in two treatment systems: reference and test, in order to compare the changes that were introduced in the time period between January and May 2016. The hydraulic conditions between the flocculation chamber and the sedimentation tank were changed in the test system, leaving the reference system unchanged for comparative purposes. The height-wise positioning of the sedimentation tank relative to the flocculation chamber resulted in a formation of a cascade at the flocculation chamber drain at a height of $0.60 \mathrm{~m}$. Air was therefore introduced into the water, forming an air-water mixture, which disturbed the flow between the devices. It was found that floc transported by the pipeline was broken down, which hampered sedimentation in the sedimentation tank. This was confirmed by the analysis of chosen parameters from treated water. After changes in the hydraulic system, changes in water turbidity were noticed, indicating an increase in post-coagulation suspension separation effectiveness. Consequently, an increase in organic carbon removal was found relative to the reference system. This change influenced changes in $\mathrm{UV}_{254}$ absorbance to a much lesser extent.
\end{abstract}

\section{Introduction}

Coagulation is a process that has been commonly used for many years in water treatment technology, especially for surface water. This process aims to effectively remove organic substances [1,2], especially oxidation or disinfection by-product precursors (OBP/DPB) [3], whose formation potential is related to UV absorbance at $254 \mathrm{~nm}\left(\mathrm{UV}_{254}\right)$ [4]. Due to the very high variability in surface water content during the year, and the varying levels of contamination dependent on source location, it is important to ensure maximum coagulation effectiveness, which influences subsequent processes in the water treatment system and their effectiveness. Optimization of the coagulation process is even more difficult due to the presence of many types of coagulants on the market and the influence on many factors on this process [5-7].

\footnotetext{
*Corresponding author: aleksandra.sambor@pwr.edu.pl
} 
Despite many studies worldwide concerning methods of conducting this process, its effectiveness, and factors influencing organic substance removal, little attention is focused on the influence of hydraulic conditions during water transport between the devices used for coagulation and sedimentation processes.

In analyses, the impact of improper water transport and flow conditions from one treatment point to another is not taken into account, and the possibility of breaking flow continuity is not considered at all.

This work presents the effect of a design error in the hydraulic installation between the flocculation chamber and the sedimentation tank on coagulation process effectiveness.

The hydraulic installation details are described in the article by Szerzyna et al [8]. Problem description

The existing water treatment system is of a conventional configuration:

coagulation $\rightarrow$ sedimentation $\rightarrow$ sand filters $\rightarrow$ ozonation $\rightarrow$ carbon filters $\rightarrow$ disinfection.

During operation a low flocculation process effectiveness was found. Two possible causes were identified:

- $\quad$ suboptimal operating settings of the slow mixing

- $\quad$ error in the water transportation system from floculation chamber $\rightarrow$ sedimentation tank. Changes in coagulant type and mixer operating parameters did not improve process efficiency, and therefore a decision was made to change the hydraulic installation.

\section{Hydraulic conditions of the water treatment system}

Prior to change, water from the slow mixing chamber drained by a PVC pipe of a DN110 diameter, then straight down via a $0.7 \mathrm{~m}$ PVC DN110 pipe and a 0.7 PCV DN63 pipe, and then via a PVC DN63 $7.5 \mathrm{~m}$ long pipeline into the sedimentation tank. The height-wise positioning of the sedimentation tank relative to the flocculation chamber resulted in a formation of a cascade at the flocculation chamber drain at a height of $0.60 \mathrm{~m}$ (fig. 1).

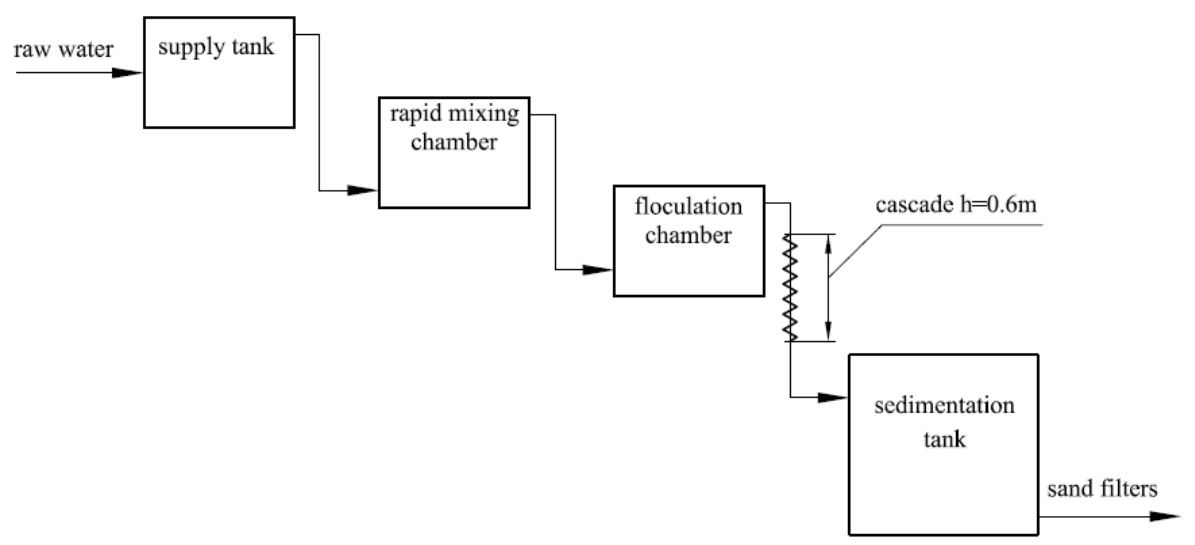

Fig. 1. Schematic of test water treatment system before changes.

Air was therefore introduced into the water, forming an air-water mixture, which disturbed the flow between the devices. It was found that floc transported by the pipeline was broken down, which hampered sedimentation in the sedimentation tank. In order to increase flocculation process effectiveness, it was decided to eliminate the cascade between the floculation chamber and sedimentation tank. After analyzing the technical possibilities and rejecting variants requiring changes in water levels in the floculation chamber, it was decided to generate linear or local hydraulic loss head of $0.60 \mathrm{mH}_{2} \mathrm{O}$. 


\subsection{Calculation assumptions - case studies}

Calculation were conducted according to PN-76/M-34034.

Hydraulic losses are:

$$
\Delta \mathrm{h}=\Delta \mathrm{h}_{\mathrm{l}}+\Delta \mathrm{h}_{\mathrm{m}}
$$

where: $\Delta \mathrm{h}_{1}-\mathrm{a}$ linear hydraulic loss head, $\mathrm{m}$,

$\Delta \mathrm{h}_{\mathrm{m}}$ - a local hydraulic loss head, $\mathrm{m}$.

$$
\begin{gathered}
\Delta \mathrm{h}_{\mathrm{l}}=\lambda \cdot \frac{L}{\mathrm{~d}_{\mathrm{w}}}+\frac{v^{2}}{2 g} \\
\Delta \mathrm{h}_{\mathrm{m}}=\xi \frac{v^{2}}{2 g}
\end{gathered}
$$

where: $\quad \lambda-\mathrm{a}$ nondimensional coefficient of linear resistance,

$\xi$ - a nondimensional coefficient of local resistance,

$\mathrm{L}$ - the length of a pipeline, $\mathrm{m}$,

$v-$ the average flow rate of liquid, $\mathrm{m} / \mathrm{s}$,

$\mathrm{g}$ - the acceleration of gravity, $\mathrm{m} / \mathrm{s}^{2}$.

For this calculation the following assumptions were made:

- the average volume flow $Q_{\text {śr }}=3.0 \mathrm{~m}^{3} / \mathrm{h}$,

- the average flow rate of liquid $v=0.4 \div 0.6 \mathrm{~m} / \mathrm{s}$.

- generation of hydraulic loss head of $0.6 \mathrm{mH}_{2} \mathrm{O}$,

- avoidance of any sudden changes in cross-section, so that the transported liquid does not undergo significant accelerations.

\subsection{Generation of local hydraulic loss head}

The potential local hydraulic loss generators were taken to be a DN50 plug valve or a DN50 butterfly valve. The generator location was taken to be in the PVC DN63x2.4 pipeline between the floculation chamber and the sedimentation tank, after the existing cascade (fig. 2).

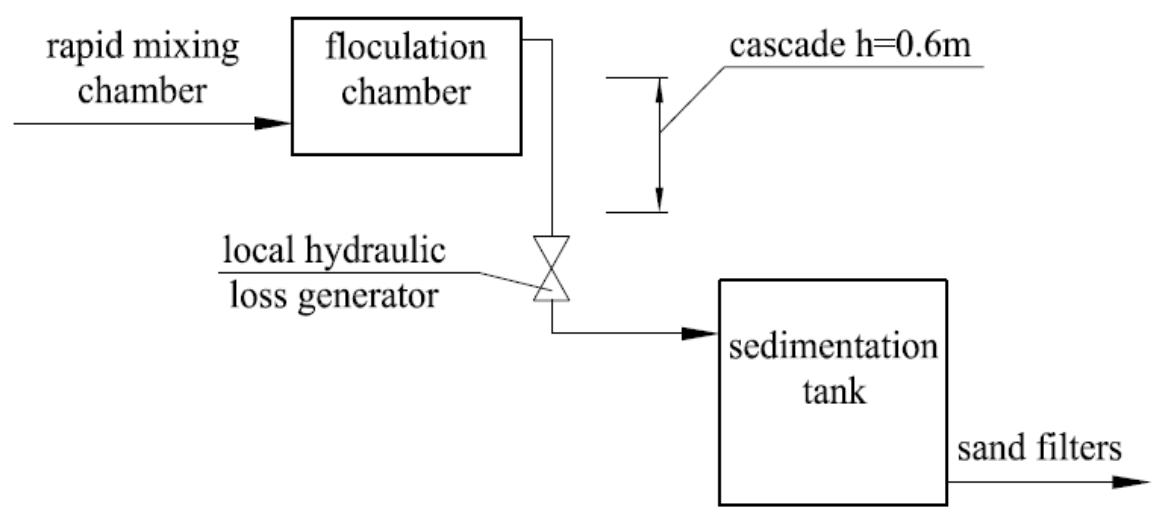

Fig. 2. Schematic with the local hydraulic loss generator placed in the system.

Based on equation (3), assuming a constant flow velocity in the installation, the required local resistance coefficient value for a one-point generator was calculated to be $\xi=122,5$. This value of $\xi$ could be obtained by restricting the plug valve by $55^{0}$ or restricting the butterfly valve by $60^{\circ}$. However, such a large restriction would result in sudden local fluid 
acceleration, which would have an adverse impact on the floc-water mixture transported by this pipeline. Furthermore there would be no guarantee of ensuring a constant volume flow.

\subsection{Generation of linear hydraulic loss head}

The linear hydraulic loss generator was taken to be an flexible PE hose coiled helically around a vertical axis. The generator location was taken to be in the PVC DN63x2.4 pipeline between the floculation chamber and the sedimentation tank, after the existing cascade (fig. 3 ). The hose diameter was calculated from the assumed range of velocities and average volume flow rate.

$$
d_{w}=\sqrt{\frac{4 Q_{\dot{s} r}}{\pi v}}
$$

The range of acceptable inside diameters $d_{w}$ of the hose was from $42.10 \mathrm{~mm}$ to $51.52 \mathrm{~mm}$. For further considerations it was assumed that $\mathrm{d}_{\mathrm{w}}=50 \mathrm{~mm}$ (DN50).

According to studies by Weissbach, for flow in a circular arc, the local resistance coefficient $\xi$ is:

$$
\xi=\left[\left(0.131+0.163\left(\frac{d}{R}\right)^{3.5}\right] \cdot \frac{\Theta}{90^{\circ}}\right.
$$

where: $d-$ the inside diameter of a pipe, $m$,

$\mathrm{R}$ - radius of curvature, $\mathrm{m}$,

$\Theta-$ arc angle, ${ }^{0}$.

Equation (5) does not take into account linear losses, which should be calculated according to (2). Due to the use of a flexible hose, which when coiled was deformed due to its own mass and the mass of water, an equivalent diameter was calculated according to (6):

$$
\mathrm{d}_{\mathrm{z}}=\frac{4 \mathrm{~A}}{U}
$$

where: $d_{z}-$ the equivalent diameter of a pipe, $m$,

A - the cross-section area of pipe, $\mathrm{m}^{2}$,

$\mathrm{U}$ - wetted diameter, $\mathrm{m}$.

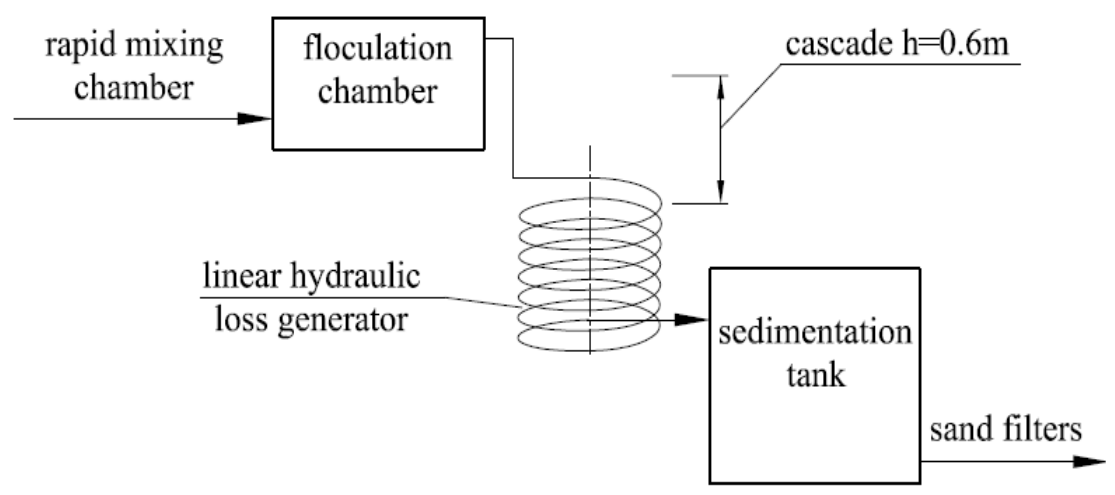

Fig. 3. Schematic with the linear hydraulic loss generator placed in the system .

Based on equation (6) the equivalent diameter of the pipeline was $d_{z}=48.1 \mathrm{~mm}$. The bending pitch diameter of the coiled hose was assumed to be $2 \mathrm{R}=0.9 \mathrm{~m}$. After calculating per (5) the local resistance coefficient caused by bending of pipeline, the local hydraulic loss head for one coil was:

$$
\Delta \mathrm{h}_{\mathrm{m}(\text { for } 360)}=5.63 \cdot 10^{-3} \mathrm{~m} \text {. }
$$


Value $\lambda$ - of a nondimensional coefficient of linear resistance calculated according to the Colebrook - White formula (7):

$$
\lambda=\left[-2 \log \left(\frac{2.51}{\operatorname{Re} \sqrt{\lambda}}+\frac{\mathrm{k}}{3.71 \mathrm{~d}}\right)\right]^{-2}
$$

where: $\mathrm{k}-$ the absolute roughness of a pipeline, $\mathrm{m}$,

$$
\mathrm{Re}-\text { the Reynolds number. }
$$

Inserting values into the equation (7) gave the linear resistance coefficient value of $\lambda=0.064$. The linear hydraulic loss head for one coil taking into account the equivalent diameter, the coefficient $\lambda$ and a unit length of $\mathrm{L}=2.83 \mathrm{~m}$, amounted to:

$$
\Delta \mathrm{h}_{1 \text { (for } \mathrm{L}=2.83)}=40.43 \cdot 10^{-3} \mathrm{~m} \text {. }
$$

Therefore the total hydraulic losses for a unit length $\Delta \mathrm{h}_{1}$ according to (1) amounted to:

$$
\Delta \mathrm{h}_{1}=\Delta \mathrm{h}_{1 \text { (for L }=2.83)}+\Delta \mathrm{h}_{\mathrm{m} \text { (for } 360)}=40.43 \cdot 10^{-3}+5.63 \cdot 10^{-3}=46.06 \cdot 10^{-3} \mathrm{~m} \text {. }
$$

The required correction was obtained by the use of 13 coils with a coil diameter of $\mathrm{D}=1 \mathrm{~m}$. The total length of DN50 flexible PE hose amounted to $36.9 \mathrm{~m}$.

\section{Verification of improvements during flocculation}

The change in water flow conditions from the flocculation chamber into the sedimentation tank caused a decrease in turbulence, and therefore yielded better conditions for flocculation and transport of flocs. Consequently, there was an almost $10 \%$ increase in organic carbon removal effectiveness (fig. 4). This was likely connected with laminar floc flow and limiting of floc break-up that occurred in the installation before the change.

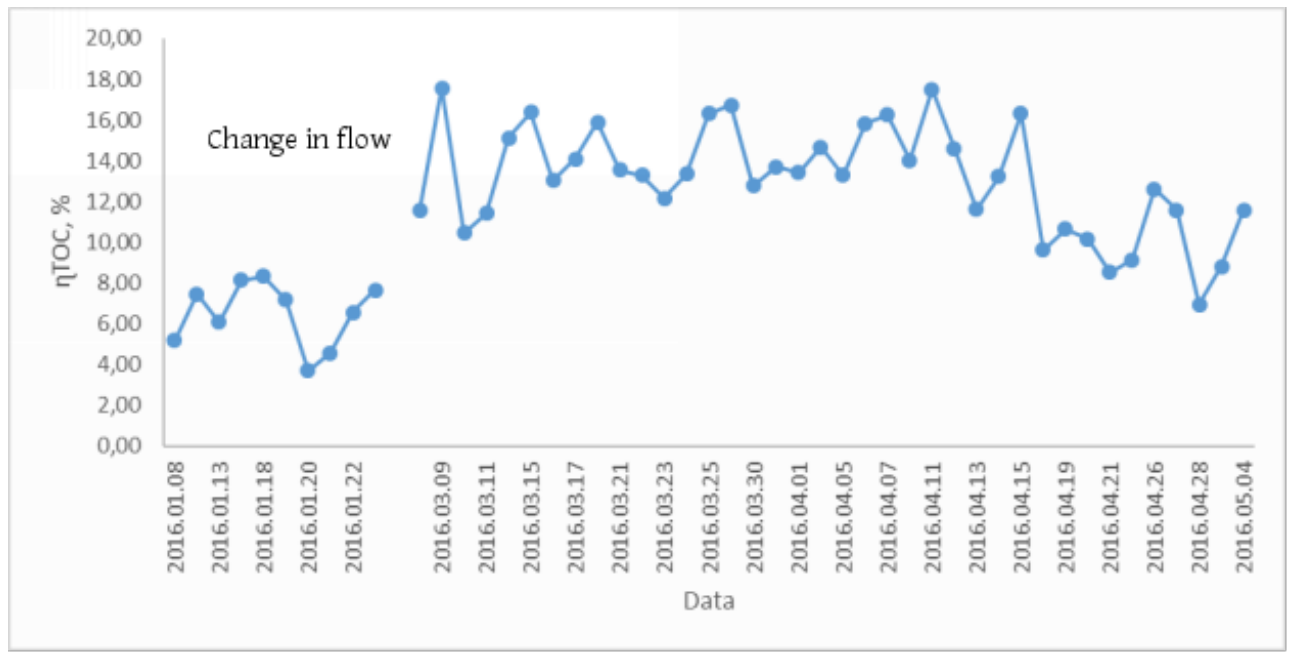

Fig. 4. TOC removal effectiveness during coagulation and sedimentation processes (test system - laboratory results).

The increase in effectiveness that was found was not accompanied by a decrease in source water quality, which might have improved the effectiveness of the coagulation process. However, no effect of installation change was found on $\mathrm{UV}_{254}$ absorbance and water colour. This is indicates removal of smaller organic substances which do not affect water colour.

The improvement in flocculation conditions contributed however to changes in turbidity reduction effectiveness for water undergoing sedimentation and coagulation (fig. 5). In the initial phase after changes in the hydraulic flow, the turbidity reduction effectiveness was comparable to that found in the second (reference) water treatment system. After about 3 
weeks, the inner surfaces of the pipeline became covered with sludge/biofilm, which contributed to increases in removing suspended particles after coagulation and sedimentation processes. This condition continued for several months of operation, which may indicate a permanent improvement in sedimentation conditions, and therefore an improvement in the turbidity reduction effectiveness.

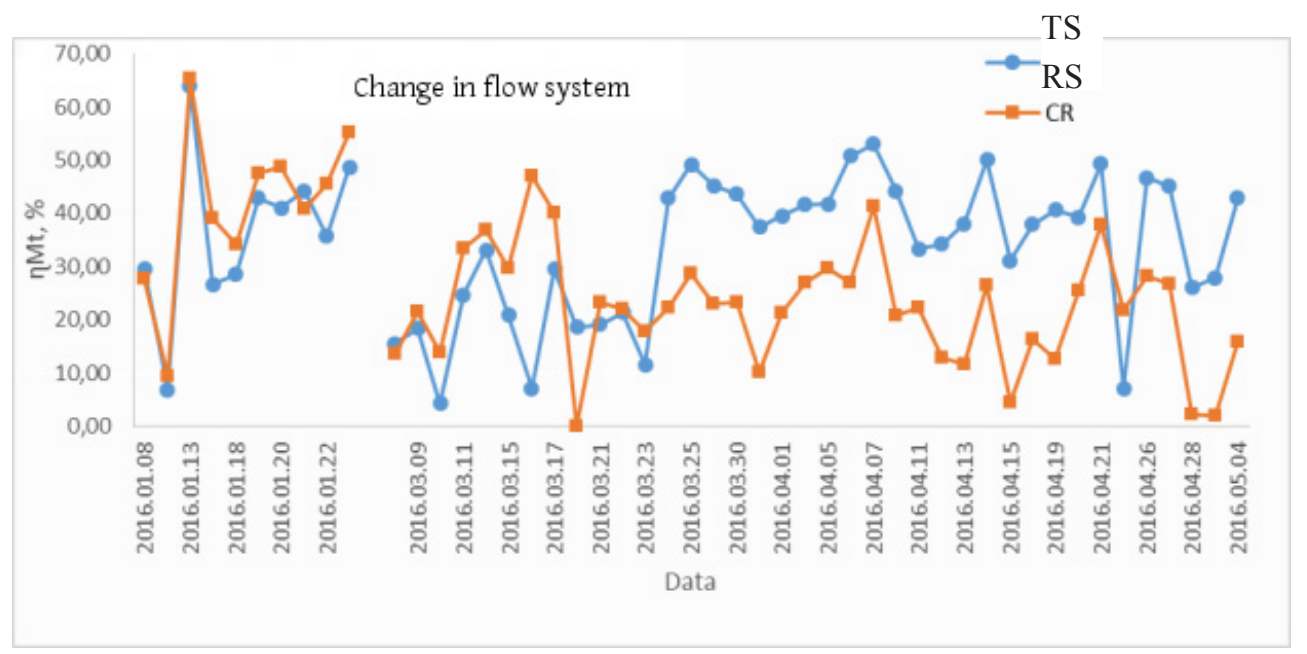

Fig. 5. Comparison of reduction in turbidity during coagulation and sedimentation processes (TS-test system, RS-reference system).

The resulting improvement in water quality after coagulation and sedimentation is connected with an increase in flocculation, which took place in the pipes connecting the flocculation chamber with the sedimentation tank.

\section{Conclusions}

The incorporation of the linear hydraulic loss generator significantly improved water quality after coagulation and sedimentation. Consequently, an increase in removing organic carbon and a decrease in water turbidity was observed, reducing disinfectant usage.

However, this change had no impact on $\mathrm{UV}_{254}$ absorbance and water color.

This increase in organic substance removal effectiveness from water clearly shows that the water treatment process is not only dependent on the performance of the individual processes, but also the conditions in which the medium is transported between the individual devices.

\section{Acknowledgments}

This publication was made possible by the National Center for Research and Development grant (PBS3/B9/44/2015) "Research on effectiveness of new water treatment technology as a step towards a shift in thinking about water utility sector" (WODTECH), and thanks to involvement of both project consortium members (Wroclaw Municipal Waterworks and Drainage Company and Wroclaw University of Science and Technology). 


\section{References}

1. E. E. Chang, P. C. Chiang, H. J. Hsing, S. Y. Yeh, Practice Periodical of Hazardous, Toxic and Radioactive Waste Management, (2007)

2. B. Bolto, D. Dixon, R. Eldridge, S. King, K. Linge, Water Res., 36 (2002)

3. L. Qi, H. Wang, X. Zheng, G. Li, Desalination and Water Treatment, 50 (2012)

4. P.C. Chiang, E.E. Chang, C.H. Liang, Chemosphere, 46 (2002)

5. M. Świderska-Bróż, M. Rak, Arch.Ochr. Środ., 30, 2 (2004)

6. S. Lee, J. Cho, H. Shin, B. Son, S. Chae, J. Water Supply Res. T., (2003)

7. Y-L. Lin, P-Ch. Chiang, E-E Chang, J. Hazard Mater, 146 (2006)

8. S. Szerzyna, M. Mołczan, M. Wolska, W. Adamski, J. Wiśniewski, International Water Association (2016). 